\title{
Maximum Power Extraction from Wind Generation System Using MPPT Control Scheme through Power Electronics Converters
}

\author{
SAFIULLAH FAQIRZAY ${ }^{1}$, H. D. PATEL ${ }^{2}$ \\ ME Student of Electrical Department, LD College of Engineering, Ahmedabad, India ${ }^{1}$ \\ Professor of Electrical Department, LD College of Engineering, Ahmedabad, India²
}

\begin{abstract}
This paper Proposes Maximum Power Extraction from Wind Turbine with permanent magnet synchronous generator, using MPPT (Maximum Power Point Tracking) control scheme with the help of regulating the dc link Voltage through Boost converter. This MPPT control scheme is applied by using directly the voltage and current of the generator which is much accurate then getting the parameters from the mechanical and other relative transducers will reduce the accuracy and cost. Feasibility of this control become possible from the relation of the power to the rotor speed and the speed is then related to the DC voltage on the rectifier's side.

The components in this wind generation system are Wind Turbine as Prime Mover, PMSG (permanent magnet synchronous generator), rectifier for converting the ac three phase voltage of the PMSG to DC Voltage, Boost converter which will control the DC Voltage of the rectifier and we will have relative speed for the extraction of maximum power from the wind turbine, and a PWM inverter which will invert the DC Voltage supplied by PMSG through rectifier and boost converter to AC Voltage for the load or the grid.

The simulation is done with help of MATLAB/SIMULINK and the result is shown which prove that the maximum power point tracking algorithm is suitable for wind turbine.
\end{abstract}

Keywords: Maximum Power Extraction, Wind Turbine Generation System, Wind Energy, MPPT, PMSG, Boost Converter

\section{INTRODUCTION}

The daily increment in using convention or non-renewable energy will lead us to a much polluted environment in future. Thus, the conventional non-renewable sources are replace by developed, clean and renewable energy sources such as solar and wind energy.

The amount of conventional energy all over the world is limited and becoming scarce after centuries of exploitation Most of these energy supplies will be depleted in the future if the current use of these resources continues at the present rate, That is why the interest increase in the renewable energy which wind energy is one of the main renewable energy sources because of its advantages its cost effective, pollution free, and safety. It has proven to be the best choice among the renewable energy sources [1] which now the installation of wind energy is day by day increasing.

Major factors that have accelerated the wind-power technology development are as follows:

And now the average annual growth rate of wind turbine installation is around 30\% during last 10 years [2] and by the end of 2006 the global wind electricity generating capacity has increased to $74223 \mathrm{MW}$ from $59091 \mathrm{MW}$ in 2005[3].

Wind turbine concepts can be classified into fixed speed, and variable speed. [2] in fixed speed the efficiency will reduce because our turbine may not operate at maximum power point so the output power may be reduced but theVariable speed system have several advantages such as yielding maximum power output while developing low amount of mechanical stress compared to constant speed

Systems so we have used variable speed concept of wind turbine in this paper [4]

As we know the wind is varying the output power is also varying but in each wind speed there will be a maximum power point in that point we can get maximum power [5] that is why it is very important to use some control topology to get to that point as shown in Fig. 3 To track this point at variable wind speed various MPPT (Maximum power point tracking topologies are used and generally they can be classified into mechanically pitched control as in [6] and electrically by electronics converter.

In [7] the common types of ac generator that are possible candidates in modern wind turbine systems are as follows:

1. Squirrel-Cage rotor induction generator (SCIG)

2. wound-Rotor induction Generator (WRIG)

3. Doubly-Fed induction generator (DFIG)

4. synchronous Generator (With external field excitation) 5. permanent magnet synchronous Generator(PMSG)

From the above list 1, 3 and 5 are mainly used. Here I will be using PMSG (permanent magnet synchronous generator)because It offers better performance due to higher efficiency and less maintenance since it does not have rotor current and can be used without a gearbox because of its lower speed operation which also implies a reduction of the weight of the nacelle and a reduction of costs $[8,9]$

Till now a significant amount of research has been performed on MPPT for variable speed wind Turbines [10] Generally MPPT are based two type control scheme 
1. the optimum parameters of the speed of turbine or generator and optimum tip speed ratio

2. the electronic converters control

Most of the MPPT research has been done the $1^{\text {st }}$ type which need measuring instruments on the wind turbine side or mechanical side which increase the cost and reduce the accuracy. Some of the research has been done on the $2^{\text {nd }}$ type also which had in different ways which we had reviewed both the above type as follows:

In [5] the control is done by estimating rotor speed of PMSG from dc voltage, dc current and some known parameters.

In [9], [11] they calculated the $\lambda_{\text {opt }}, \omega_{\text {opt }}, C_{p}\left(\lambda_{\text {opt }}\right)$ then at last $P_{\text {opt }}$. Which are the optimal tip speed ratio, generator optimal speed, optimal power coefficient, and Power optimal respectively

In [12] wind turbine speed is controlled through pitch angle of movable blade means mechanically controlled which is very costly than the electronically controlled.

In [13] MPPT is applied for a wind turbine with a squirrel cage induction generator, and comprising a matrix converter (MC).

In [14] a cascaded H-bridge multilevel inverter (CHB MLI is proposed for the DC/AC conversion

Which will increase the switches and losses will be increased too.

in [15] multilevel clamped (NPC) converter is used for the Wind turbine PMSG in this type again with increasing switches the switching in the circuit and cost will increase which is not suitable. For a small wind turbine.

In [5],[9],[11],[12],[14],[24] all these MPPT are based on mechanical parameters of wind turbine which will need extra instrumentation on the mechanical side of the wind turbine that will increase the cost of controlling and reduce the accuracy.

The proposed MPPT control scheme general block diagram is shown in Fig. 1 which will not be using any parameter from the mechanical side of the turbine unless we will utilizing the available Voltage and current to get proper control of the speed of the generator through changing the dc output voltage of the rectifier by using boot converter as per the MPPT controlling signal.

And in [13],[17],[15],[16] had various electronically controlled topology which the drawbacks are explained for it earlier.

The proposed MPPT control scheme is different from the above which are used it is following the $\mathrm{P} \& \mathrm{O}$ (perturbation and Observation) but the step is calculated through Newton Raphson method and also unlike the above reviewed method We will be using Voltage as reference to get the controlling signal.

This propose topology advantages are, it doesn't need knowledge of the WG optimal power characteristic or measurement of the wind speed is required and the WG operates at a variable speed

Thus, the system features higher reliability, lower complexity and cost, and less mechanical stress of the WG.

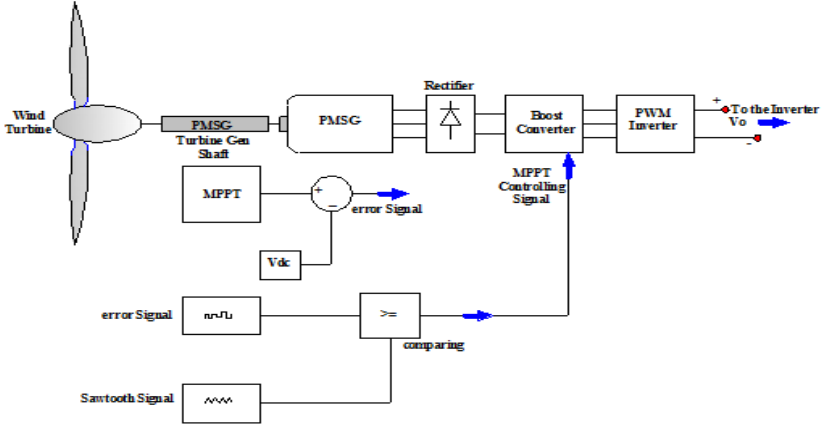

Fig. 1 General block diagram of PMSG Wind Turbine with MPPT control

\section{MECHANICAL POWER OF WIND} TURBINE

The kinetic energy in air of an object of mass m moving with speed $\mathrm{v}$ is equal to as in [13].

$E=\frac{1}{2} m v^{2}(N m)(1)$

$P_{\text {wind }}=\frac{d e}{d t}=\frac{1}{2} \dot{m} v^{2}$

Herem is the mass flow rate per second when the air passes across an area $A$, which that area is swept by the rotor blades, the power in the air can be estimated as?

$P_{\text {wind }}=\frac{1}{2} \rho A v^{3}$

Here $P_{\text {wind }}$ is the available power in the wind, $\rho$ is the air density which varies with air pressure and temperature here I will be using $\rho=1.225 \mathrm{~kg} / \mathrm{m}^{3}$ in my project.[18]

The mechanical power of the turbine can be written as:

$P_{\text {mech }}=C_{p} * P_{\text {wind }}$

Here $C_{P}$ is the power coefficient, which is the function $\lambda$ and $\beta$ as shown in Fig. 2 and as per Bet'z Law 59.3\% of the total wind can be extracted as mechanical power [19] so it means maximum value of $C_{P}=0.593$. But practically it is not possible because of the losses. Practically $C_{P}$ can derived from the following equation.

$C_{p}(\lambda, \beta)=c 1\left(\frac{c_{2}}{\lambda_{i}}-c_{3} \beta-c_{4}\right) e^{\frac{-c_{5}}{\lambda_{i}}}+c_{6} \lambda$

Here $\frac{1}{\lambda_{i}}$ is equal to:

$\frac{1}{\lambda_{i}}=\frac{1}{\lambda+0.08 \beta}-\frac{0.035}{\beta^{3}+1}$

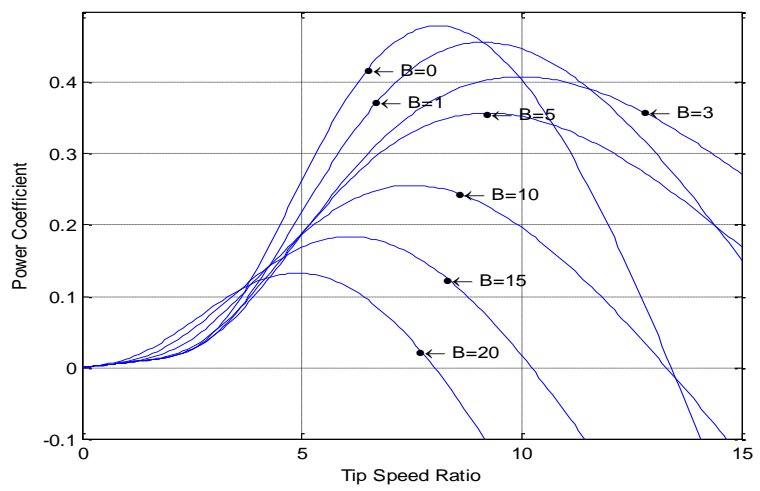

Fig. 2 Power Coefficient $C_{P}$ Versus Tip Speed $\lambda$ for different Pitch angles $\beta$ Here the coefficients are $\mathrm{c} 1=0.5176, \mathrm{c} 2=116, \mathrm{c} 3=0.4, \mathrm{c} 4$ $=5, c 5=21$, and $c 6=0.0068,[20] \beta$ is pitch angle of the 
blades and we consider it as $\beta=0$ for the maximum $C_{p}$ as shown in fig.

$\lambda=\frac{\omega * R}{V}$

Here $\omega$ turbine rotor speed in $(\mathrm{rad} / \mathrm{sec}), R$ is the radius of rotor in (meters), and $V$ is the wind speed in $(\mathrm{m} / \mathrm{sec})$.

III. ELECTRICAL GENERATION OF WIND TURBINE As we will be utilizing the proposed MPPT scheme on PMSG (permanent magnet synchronous generator here so we will find the relation of the generator speed and the dc link voltage and finally relation to the power of the generator as follows:

The voltage equation in the abc stationary reference frame for PMSG, as shown in [21], are given by,

$V_{a}=r_{s} i_{a}+\frac{d}{d t} \lambda_{a}$

$V_{b}=r_{s} i_{b}+\frac{d}{d t} \lambda_{b}$

$V_{c}=r_{s} i_{c}+\frac{d}{d t} \lambda_{c}$

Here $r_{s}$ is stator winding resistance of the PMSG, $i_{a}, i_{b}$ and $i_{c}$ are the three phase instantaneous currents

The flux linkages equations are expressed as follows,

$\lambda_{a b c s}=L_{s} i_{a b c s}+\lambda_{m}^{\prime}\left|\begin{array}{c}\sin \theta_{r} \\ \sin \left(\theta_{r}-\frac{2 \pi}{3}\right) \\ \sin \left(\theta_{r}-\frac{4 \pi}{3}\right.\end{array}\right|$

In the above equation $\lambda_{m}^{\prime}$ denotes the amplitued of the flux linkage established by permanent magnet. The stator selfinductance $L_{s}$.

The Torque and Speed can be related by electromechanical motion equation:

$J \frac{d}{d t} \omega_{r m}=\frac{P}{2}\left(T_{e}-T_{L}\right)-B_{m} \omega_{r m}$

Where, $\mathrm{J}$ is the inertia, $B_{m}$ is the approximated mechanical damping due to friction and $T_{L}$ is the load torque.

The electromechanical torque of the machine should balance the mechanical torque on rotor shaft as:

$T_{\text {mech }}=T_{\text {em }}+T_{\text {loss }}$

Here $T_{\text {mech }}$ is the mechanical Torque of the turbine, $T_{e m}$ is the generator Torque and $T_{\text {loss }}$ is the total Torque losses. In the same manner for the power balance equation we can write:

$P_{\text {mech }}=P_{\text {em }}+P_{\text {loss }}$

And here

$P_{\text {mech }}=T_{\text {mech }} * \omega_{m}$

$\omega_{m}=\omega_{\text {syn }}$

$P_{\text {mech }}=T_{\text {mech }} * \omega_{\text {syn }}$ Here $P_{\text {mech }}$ is the mechanical power supplied by the wind turbine, which is shown in Fig. 3

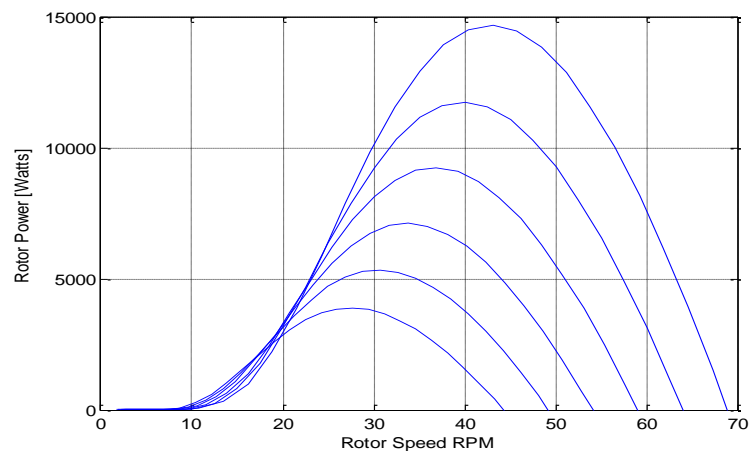

Fig. 3 Power versus Speed Characteristics of a Wind Turbine

$P_{\text {em }}=T_{\text {em }} \omega_{\text {syn }}$ Is the power of the generator, $P_{\text {loss }}=$ $T_{\text {loss }} \omega_{\text {syn }}$ is the mechanical power loss of the system. The generated power can be written as:

$P_{\text {em }}=T_{\text {em }} \omega_{\text {syn }}=3 E_{a} I_{a} \cos \left(\varphi_{E_{a} I_{a}}\right)$

Here $\varphi_{E a I a}$ is the angle between phasors $E_{a}$ and $I_{a}$.

If we ignore the phase winding resistance then output electrical power can be written as,

$P_{\text {em }}=P_{\text {out }}=3 V_{a} I_{a} \cos \phi$

In the above equation $\phi$ is the difference of angle between $V_{a}$ and $I_{a}$. And if we assume the power factor as Unity then we can write that:

$P_{\text {out }}=3 V_{a} I_{a}$

\section{AC TO DC UNCONTROLLED RECTIFIERS}

Here we will be using three phase full bridge rectifier which contain positive commutating diodes $D_{1}, D_{2}, D_{3}$, and negative commutating diode group $D_{4}, D_{5}$, and $D_{6}$. In any time there will be only two diodes conducting, one from positive group one from negative and output voltage is given by,

$v_{o}=v_{p n}-v_{N n}$

Here $v_{p n}$ and $v_{N n}$ are the output voltages of the positive and negative commutating diodes groups to neutral respectively. If we assume that the $L_{s}$ is equal to $\operatorname{zero}\left(L_{s}=\right.$ 0 ) the average output voltage can be written as:

$V_{o}=\frac{1}{\frac{\pi}{3}} \int_{-\frac{\pi}{6}}^{\frac{\pi}{6}} \sqrt{2} V_{L L} \cos (\omega t) d(\omega t)$

$V_{o}=\frac{3 \sqrt{2}}{\pi} V_{L L}=1.35 V_{L L}$

Practically $L_{S}$ is non zero there for the current through incoming diode will build up gradually and the current through the outgoing diode will decrease gradually. And this effect will cause the current overlap so the average dc output voltage become

$V_{d c}=1.35 V_{L L}-\frac{3}{\pi} X_{S} I_{d}$

\section{BOOST CONVERTER}

Boost converter is dc to dc step up converter which we will use it for regulation of the dc voltage here

The principle of operation is given in [22]

If the switch is on than the voltage across the inductor is $V_{\text {in }}$ and the current through that will be as: 
$I_{L}(t)=\frac{1}{L} V_{\text {in }} t+I_{L}(0) \quad 0 \leq t \geq D t$

Which $I_{L}(0)$ is the initial inductor current at time $t=0, \mathrm{D}$ is the duty cycle and $\mathrm{T}$ is the period. In mode 2 the inductor voltage is $V_{\text {in }}-V_{0}$ and the current will be:

$i_{L}(t)=\frac{1}{L}\left(V_{\text {in }}-V_{0}\right)(t-D T)+I_{L}(D T) \quad D T \leq t \geq T$

(25)

Solving the equation (24) and (25) at $\mathrm{t}=\mathrm{DT}$ and $\mathrm{t}=\mathrm{T}$, and also assuming that $I_{L}(T)=I_{L}(0)$,

We get the voltage conversion equation as

$\frac{V_{o}}{V_{\text {in }}}=\frac{1}{1-D}$

$V_{o}=\frac{V_{\text {in }}}{1-D}$

Duty cycle can be derived as follow:

$D=\frac{T_{\text {on }}}{T_{\text {on }}+T_{\text {off }}}$

\section{PROPOSED MPPT}

The MPPT control scheme and the equations which are used are given in the flowchart in Fig. 4

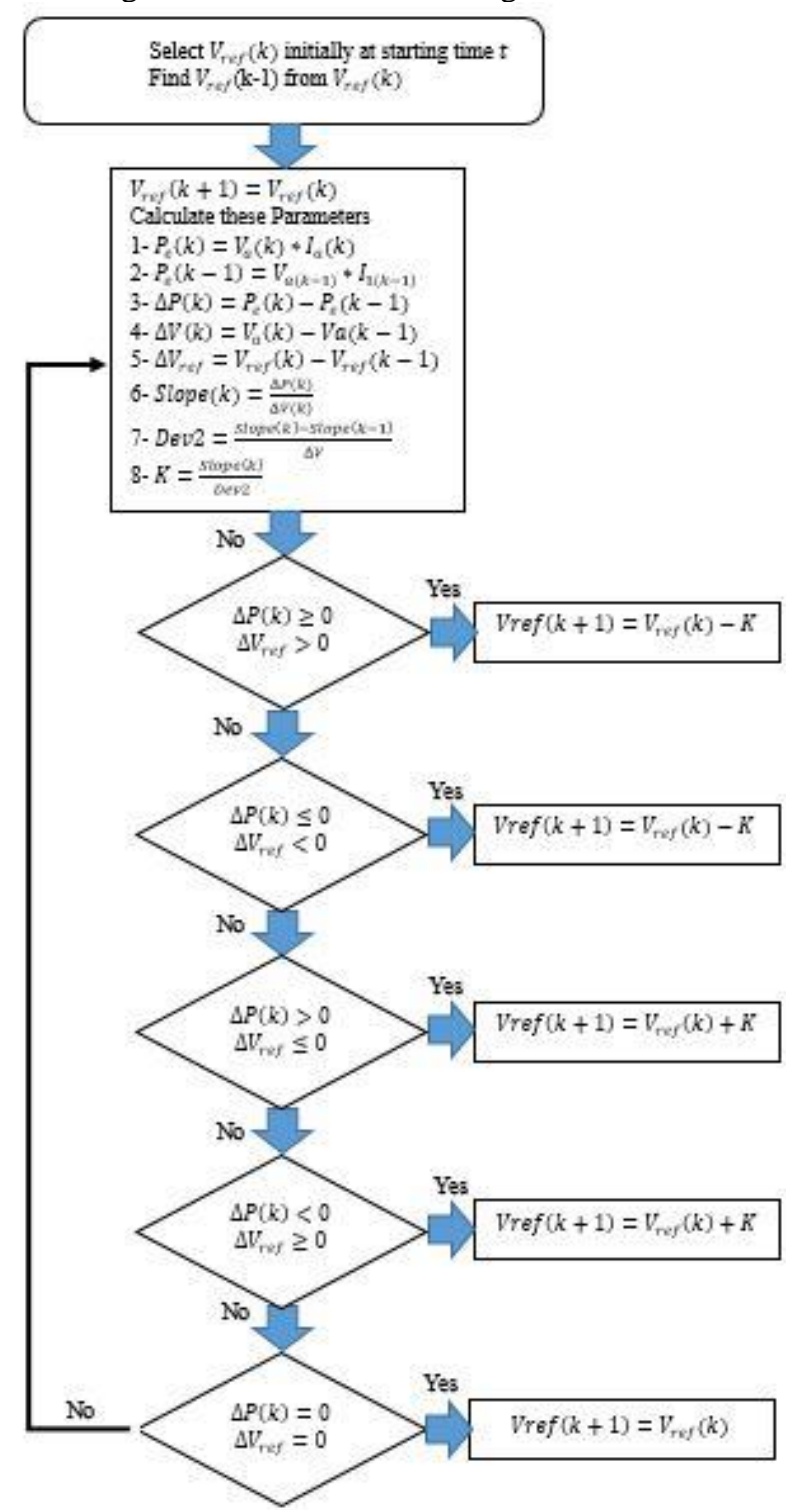

Fig. 4 Proposed MPPT Flowchart
In the above flowchart:

$V_{a}(k)$ is dc output voltage of the rectifier $I_{a}(k)$ is dc output current of the rectifier $V_{a}(k-1)$ is one sample delayed of $V_{a}(k)$ $I_{a}(k-1)$ is one sample delayed of $I_{a}(k)$ $P_{e}(k)$ is the generated of PMSG

$P_{e}(k-1)$ is one sample delayed of $P_{e}(k)$

$\Delta P(k)$ is the difference between $P_{e}(k)$ and $P_{e}(k-1)$

$\Delta V(k)$ is the difference between $V_{a}(k)$ and $V_{a}(k-1)$ $V_{\text {ref }}(k)$ is the initial selected reference voltage $V_{\text {ref }}(k-1)$ is one sample delayed of the $V_{\text {ref }}(k)$ $V_{\text {ref }}(k+1)$ is one sample advance of the $V_{\text {ref }}(k)$ $\Delta V_{\text {ref }}$ is the difference between $V_{\text {ref }}(k)$ and $V_{\text {ref }}(k-1)$ Dev2 is the second derivative of the slope.

$K$ is the changeable step.

The method is explained in the following figure

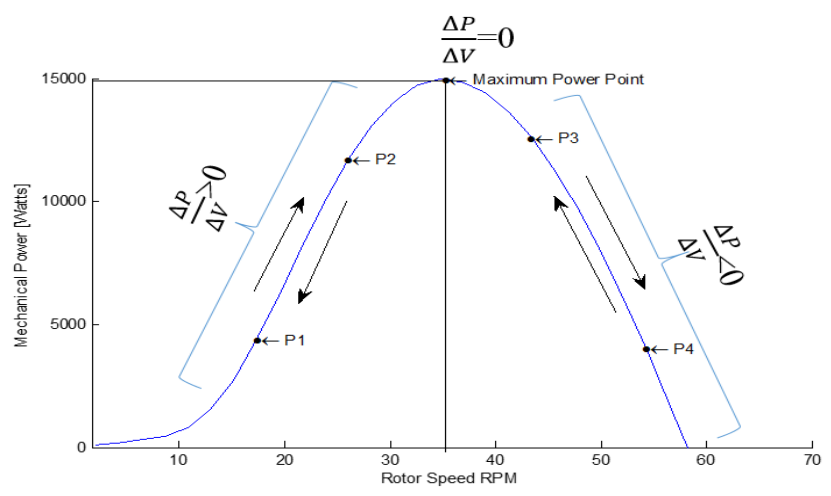

Fig. 5 Relation of Mechanical power $P_{\text {mech }}$ Versus Generator speed $\omega$ As we know that $\frac{d P}{d V}=\operatorname{slop}=\frac{\Delta P}{\Delta V}$

And from the slop we know that:

1. If $\frac{\Delta P}{\Delta V}<0$ the generator is operating on high speed means on p3 (point3) and p4 (point4) side in the Fig. 5

2. If $\frac{\Delta P}{\Delta V}>0$ the generator is operating on the low speed side on $\mathrm{p} 1$ and $\mathrm{p} 2$ side in Fig. 5

3. If $\frac{\Delta P}{\Delta V}=0$ then it is operating on the maximum point

Two conditions are explained as an example here:

1. Generator speed is increasing from P1 to $\mathrm{p} 2$ so we can write that:

$P_{2}>P_{1}=>\Delta P=P_{2}-P_{1}=>\Delta P>0$

And accordingly for $\Delta V$ we can have that $V_{2}>V_{1}=\Delta V=V_{2}-V 1=\Delta V>0$

Then we add a $K$ step to the $V_{\text {ref }}$ means that $V_{\text {ref }}(k+1)=V_{\text {ref }}+K$

2. Generator speed is decreasing from $\mathrm{P} 4$ to $\mathrm{p} 3$ so we can write:

$\Delta P=P_{4}-P_{3}>0 \& \Delta V=V_{4}-V_{3}<0$ then in this condition we reduce a step of voltage to reduce the speed as:

$V_{\text {ref }}(k+1)=V_{\text {ref }}(k)-K$ 


\section{Parameters}

TABLE1

WIND TURBINE PARAMETERS

\begin{tabular}{|l|c|c|l|}
\hline Parameter & Symbol & Value & Unit \\
\hline Out Power & $P_{\text {mech }}$ & 15000 & Watts \\
\hline Cut-in wind speed & $V_{\text {cut-in }}$ & 3.5 & $\mathrm{~m} / \mathrm{sec}$ \\
\hline Rated Wind speed & $V_{\text {rated }}$ & 12.5 & $\mathrm{~m} / \mathrm{sec}$ \\
\hline Pitch angle & $\beta$ & $0^{\circ}$ & degree \\
\hline Turbine Rotor Radius & $R$ & 2.8 & $\mathrm{~m}$ \\
\hline
\end{tabular}

TABLE2

GENERATOR PARAMETERS

\begin{tabular}{|l|c|l|l|}
\hline Parameter & Symbol & Value & Unit \\
\hline Rated dc Voltage & $P_{e}$ & 15000 & Watts \\
\hline Rated Power & $V_{\text {o.rated }}$ & 361 & Volts \\
\hline Stator inductances & $r$ & 0.087 & ohms \\
\hline Stator resistance & $L_{d}, L_{q}$ & 2.49 & $\mathrm{mH}$ \\
\hline Flux induced by magnets & $\lambda_{m}$ & 0.398 & $\mathrm{~Wb}$ \\
\hline Moment of inertia & $\mathrm{J}$ & 0.296 & $\mathrm{Kg} . \mathrm{m}^{2}$ \\
\hline Number of Poles & $P$ & 4 & - \\
\hline
\end{tabular}

TABLE3

BOOST CONVERTER PARAMETERS

\begin{tabular}{|l|c|l|c|}
\hline Parameter & $\begin{array}{l}\text { Sym } \\
\text { bol }\end{array}$ & Value & Unit \\
\hline Power Rating & $P$ & 15000 & Watts \\
\hline Generator side capacitor & $C_{1}$ & 10 & $\mathrm{mF}$ \\
\hline Load side capacitor & $C_{0}$ & 30 & $\mathrm{mF}$ \\
\hline Inductor & $L$ & 0.013986 & $\mathrm{mH}$ \\
\hline Switching frequency & $F_{d c}$ & 10 & $\mathrm{kHz}$ \\
\hline
\end{tabular}

\section{A.}

VIII. SIMULATION AND RESULTS

\section{A. FIRST WIND PATTERN}

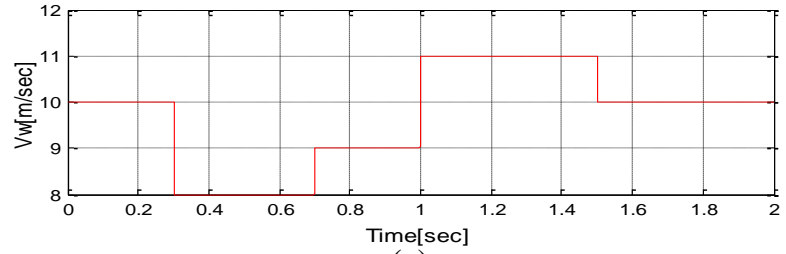

(a)

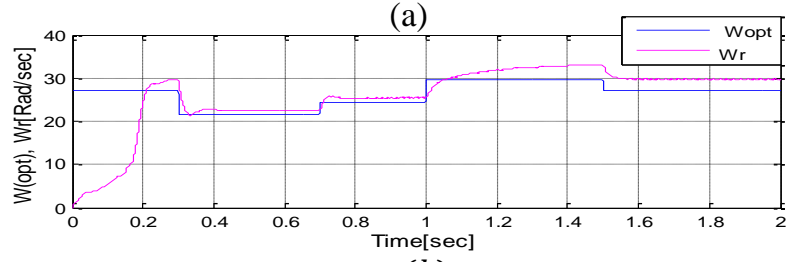

$(b)$

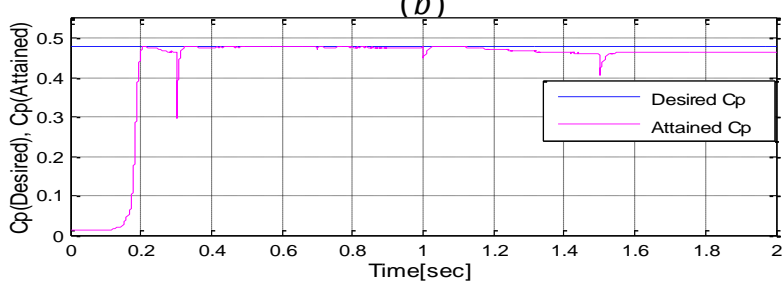

(c)

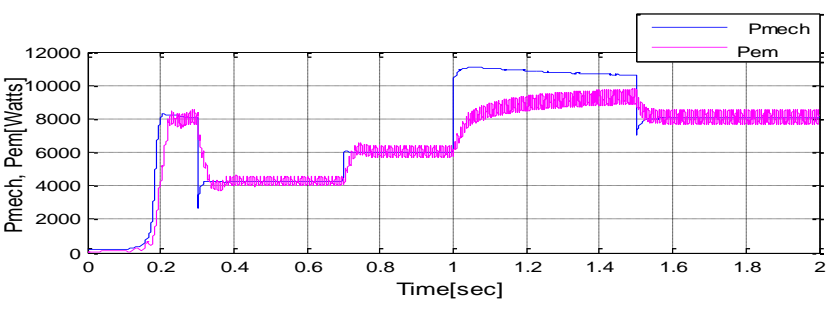

(d)

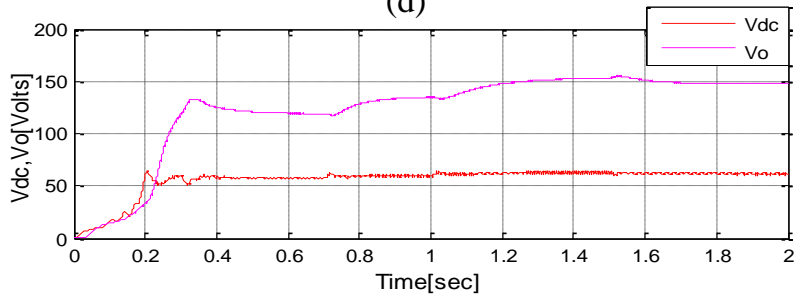

(e)

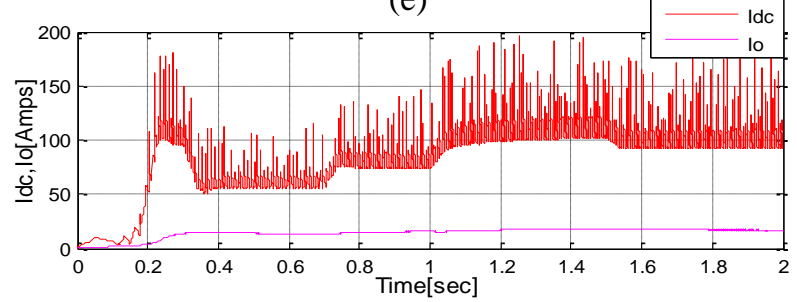

(f)

Fig. 6 simulation results of the PMSG WG in matlab SIMULINK, a) Wind Pattern Versus (VS) Time, b) Genetor attained speed Wrand optimal speed for maximum Power Wopt VS Time, c) Desired and attained power coefficient VS Time, d) mechanical power Pmech and Electrical power Pem VS time, e) boost converter input Voltage Vdc and boost converter output voltage Vo versus time, f) boost converter input current Idc and boost converter output current Io versus time,

B. SECOND WIND PATTERN

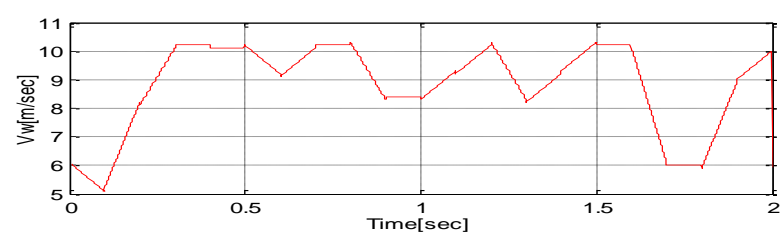

(a)
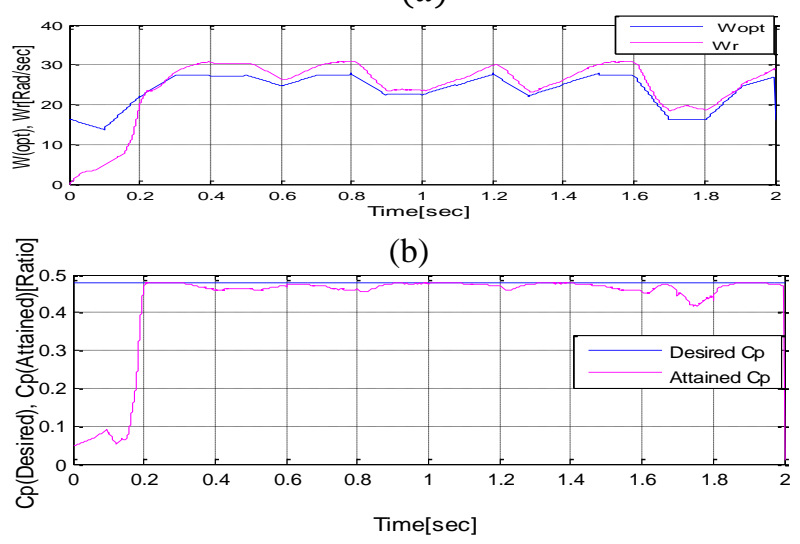

(c) 


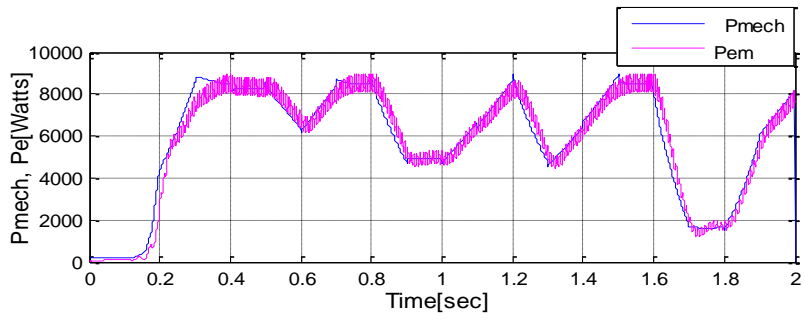

(f)

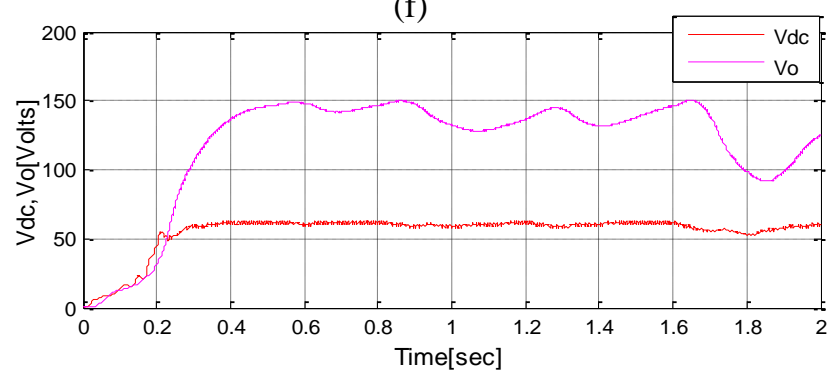

(e)

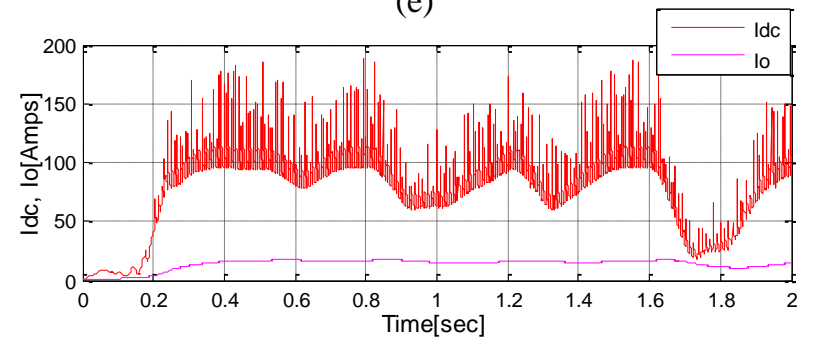

(f)

Fig. 7 simulation results of the PMSG WG in matlab SIMULINK, a) Wind Pattern Versus (VS) Time, b) Genetor attained speed $W r$ and optimal speed for maximum Power Wopt VS Time, c) Desired and attained power coefficient VS Time, d) mechanical power Pmech and Electrical power Pem VS time, e) boost converter input Voltage Vdc and boost converter output voltage Vo versus time, f) boost converter input current Idc and boost converter output current Io versus time,

\section{CONCLUSION}

We have developed an MPPT control scheme for a PMSG wind turbine in MatLab SIMULINK. The speed control of PMSG which is connected with the rectifier, then to the boost converter is done with the help of switching of the boost converter, regulate the voltage and finally the speed of the PMSG to get to Maximum coefficient where the maximum power can be extracted.

In the simulation two wind patternsare taken as samples and as it seem from the results the PMSG is tracking the MPP (Maximum Power Point) quiet efficiently and fast so this control system is suitable can be applied in small wind turbine.

\section{REFERENCE}

[1] Prselvi T, Ranganath Muthu Wind Energy Conversion System with Boost Converter and CHB MLI with single DC input, Porselvi T et al./ International Journal of Engineering and Technology IJIET, 2014

[2] H.Li, Z.Chen, Overview of different wind generator system and their comparisons, IET Renewable Power Generation 2007

[3] Zhe Chen, Josep M. Guerrero, and Frede Blaabjerg, A Review of the state of the Art of Power Eelctronics for wind Turbines IEEE Transactions, 2009

[4] S. Samanvorakij, P. Kumkratug Modeling and Simulation PMSG based on Wind Energy Conversion System in MTLAB/SIMULIk PROC. Of the second Intl. Conf on AEEE 2013.
[5] 5-Mahmoud M. Hussein, Mohamed Orabi Simple Direct Sensorless Control of Permanent Magnet Synchronous Generator Wind Turbine 14 th internatioin middle east power systems conference (MEPCON'10) Cairo University, Egupt, 2010

[6] 6-Tomonobu Senjyu, Ryosei Sakamoto, Naomitsu Urasaki, Output power leveling of wind Turbine generator for all operating regions by Pitch Angle Control IEEE Transactions 2006.

[7] 7- Udhayakumar p, Saravanan C, Lydia M Stand - Alone Wind Energy Supply System Using PMSG Interantional Journal of Innovative Technology and Exploring Engineering (IJITEE), 2013

[8] 8- Alejandro Rolan, Alvaro Luna, Gerardo Vazquez, Daniel Aguilar, Gustavo Azevedo Modeling of a Variable Speed Wind Turbine with a PMSG IEEE International Symposium on Industrial Electronics (ISIE), 2009

[9] 9- S. Belakehal, H. Benalla and A. Bentounsi Power maximization control of small wind system using PMSG, Revue des Energies Rnouvelables, 2009

[10] 10- Choon Yik Tang, Yi Guo, and John N. Jiang

[11] Nonlinear Dual-Mode Control of Variable-Speed Wind Turbines with Doubly Fed Induction Generators, IEEE Member, 2011

[12] 11- Monica Chinchilla, Santiago Arnaltes, and Jual Carlos Burgos, control of PMG Applied to Variable-speed wind-energy system connected to the grid, IEEE Transaction 2006

[13] 12- E. Muljadi, C.P. Butterfield Pitch-controlled variable-speed wind turbine generation, Nation Renewable Energy Laboratory NREL, Presented at 1999 IEEE industry Applications.

[14] 13- S.Masoud Barakati, Mehradad Kazerani, and J. Dwight Aplevich, Maximum power tracking control for a wind turbine system including a Matrix Converter, IEEE Transaction on energy conversion, 2009

[15] 14- Hui Li, K. L. Shi and P. McLaren, Neural Network Based Sensorless Maximum Wind Energy Capture with Compesated Power Coefficient IEEE 2004.

[16] 15- G. Balaji, Dr. I. Gnanambal, S. Suganya, Power converter Topology for PMWG System, IOSR Journal of Engineering (IOSRJEN), 2013

[17] 16- V. Karthikeyan, V.J Vijayalakshmi, P. Jeyakumar, Step and Search control method to track the maximum power in winnd energy conversion systems - A Study, 2013

[18] 17- Eftichios Koutroulis and Kostas Kalaitzakis, Design of a Maximum Power Tracking System for Wind-Energy-Conversion Applications, IEEE Transactions, 2006

[19] 18- S. N. Bhadra, D. Kastha, S.Banerjee, Wind Electrical Systems Book, 12th impression 2005

[20] 19- Shrikant S Mali, B. E. Kushare, MPPT Algorithms: Extracting Maximum Power From Wind Turbines, Internationa Journal of Innovative Research in EEICE, 2013

[21] 20- Endusa Billy Muhando, Tomonobu Senjyu, Hiroshi Kinjo and Toshihisa Funabashi, Extending the Modeling Framework for Wind Generation systems: RLS-Based Paradigm for performance udner high turbulence inflow, IEEE Transactions, 2009

[22] 21- Remith K Madhu and Anna Mathew, MATLAB/SIMULINK Model of field oriented control of PMSM drive using space Vectors, IJAET, July 2013

[23] 22- Muhammad H. Rashid, Power Electronics Handbook, 2001 academic press

[24] 23- Ali M. Eltamaly, Modeling of Wind Turbine Driving PMG with MPPT system, J.King Saud Univ. Vol. 19, Eng. Sci. (2), pp. 223-237, Riyadh (1427H./2007), 2006

[25] 24- Yuu-Su Kim, Il-Yop Chung and Seung-Il Moon, An Analysis of Variable-Speed Wind Turbine Power- Control Methods with Fluctuating Wind Speed, Energies 2013,6,3323-3338; doi: 10.3390/en6073323 